\title{
The Design and Implementation of the Safety Monitoring System of the Chemical Dangerous Goods Logistics based on RFID Technology
}

\author{
YanHua Wang \\ \{wangyanhuacf@163.com\} \\ ChiFeng Industry Vocational Technology College Chifeng Inner Mongolia, 024000, China
}

\begin{abstract}
Since the beginning of the century, China's economic rapid and stable development, demand for chemical products also soared, which for and the related dangerous goods storage and transportation industry has a huge market opportunities, while also facing extremely severe challenges. Traditional warehouse management and transportation management mode has not been able to meet the needs of modern chemical enterprises, this paper combined with advanced dangerous goods management concept, put forward a new solution. Chemical material safety has been the government and enterprises pay much attention to the safety problems, based on radio frequency identification (RFID) and data acquisition (AIDC) technology, spatial database technology and web technology, chemical material safety monitoring system is to solve this problem an effective technology. The above technologies are organically integrated, used for the safety monitoring system of chemical products, the use of dangerous chemical goods, storage, transportation, tracking and traceability in real-time and fully automated management. The development and industrialization of the system will greatly improve the management level of dangerous chemical goods, reduce the environmental and safety threats, reduce the risk of emergency response time, and will greatly reduce the relevant chemical logistics chain cost.
\end{abstract}

Keywords: Radio frequency identification; data collection; spatial database; safety monitoring of chemical dangerous goods logistics

\section{Introduction}

In the rapid development of China's economy today, more and more chemical products appear in people's daily life, in the convenience of the same time, the risk of their own lives and property of the people become a major security risk. How to strengthen the management of chemical dangerous goods, reduce the occurrence of the accident, is the most important research in the chemical industry. On the other hand, although the countries from the aspects of strengthening the management of dangerous chemicals, but because at present, our country is in the period of economic transformation, construction of laws and regulations, personnel quality, basic education, infrastructure construction and other failed to and supporting the development, coupled with the nature of the dangerous goods special, easily lead to major accidents [1], so in the management of dangerous goods exposed a lot of problems, especially people's life and property safety and environmental problems have become increasingly 
prominent. In recent years, the occurrence of a series of dangerous explosive, leaks and other accidents to people's safety of life and property caused great harm, but also caused huge economic losses to the state and some accident back to the surrounding environment caused permanent damage. Strengthen the management of dangerous chemicals to reduce the accidents of dangerous goods has become a pressing issue, requires both the government's macro-control and the legal system perfect, need more use of modern high-tech means to prevent and achieve the purpose of monitoring.

In order to realize the effective management of dangerous goods, the RFID technology can be applied to the management of the program, the design of a complete set of RFID dangerous goods management system. In every chemical goods containers not reversible paste a RFID tag, in addition to a unique sequence of exon, the RFID tag does not contain any information about the object, the information can only be through the authority to verify obtained from the database. The operator can use a portable RFID power reader to record the placement and movement of the item in the storage unit. Using RFID tags of dangerous goods production, storage, transportation, use, etc., to record information, and through the network technology to guarantee the information transmission and real-time display, finally realizes the chemical dangerous goods in the whole life cycle is completely within the effective monitoring and effective management of the relevant departments.

\section{RFID System Principle and Related Technology}

The basic working principle of RFID technology is not complicated: label into the field after receiving an interpretation of a RF signal, generated by induction current energy to send the stored in the chip product information (passive tags, passive tags or passive tags), or by the label active (active tag, active tags or active tag) to send a frequency signal, the reader to read information and decoding, sent to the central information system on the data processing.

A complete set of RFID system is by the reader and tag (tag) is three part of so-called transponder (transponder) and application software, system composition, the working principle is reader launch a specific frequency radio wave energy to the transponder, used to drive the transponder circuit will be internal data sent. At this time, the reader sequentially receiving data interpretation, gave the application do corresponding processing [2].

As shown in figure 3.4. Responder also that the electronic tag is the information carrier of the RFID system. At present, most of the electronic tags are composed of the original (coil, microstrip antenna, etc.) and the micro chip components. According to the structure and technology of the reader, the reader can be read or read / write device, which is the RFID information reading and writing control and processing center. The reader is usually composed of a coupling module, a receiving module, a control module and an interface unit. The reader (Reader) is a device that reads (sometimes also can write) tag information, which can be designed for handheld or fixed, as shown in Fig. 1. The half duplex communication mode is used to exchange information between reader and transponder. In practical applications, the Fthernet or WLAN can be used to realize the collection, processing and remote transmission of the object identification information. 


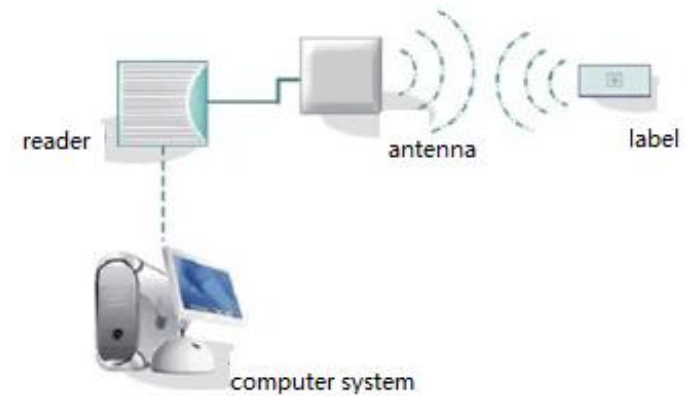

Fig. 1. Schematic diagram of RFID system structure

\subsection{GPRS technology introduction}

GPRS is the abbreviation of general packet radio service (General Packet Radio Service), which breaks through the GSM network can only provide circuit switching mode of thinking, only by increasing of the corresponding functional entities and part of the reconstruction of the existing base station system to achieve packet switching, the renovation of the investment is relatively small, but get user data rates are considerable. GPRS is a global system for mobile (GSM) based data transmission technology, can be said to be an extension of GSM, and can complete some of the existing service. For example: the cellular telephone circuit exchange (circuit switched) connection and short message service (SMS). GPRS and the past continuous in the transmission channel way different. It is based on the packet to transfer, so the cost borne by the user is calculated by the transmission unit of information, does not use the entire channel. The theory is relatively cheap. Another feature of GPRS is that its transmission rate can be increased to 56 or even $114 \mathrm{KbPs}$. Moreover, the connection and the transmission can be more convenient and easier because no need for the intermediate converter of the current wireless application. GPRS network is based on the existing GSM network to achieve. In the existing GSM network, some nodes need to be added, such as GGSN (GPRS Supporting Node Gateway, gateway GPRS support node) and SGSN (GSN Serving, GPRS support node). Mobile communication technology from the first generation of analog communications system to the second generation of digital communication systems, and after the $4 \mathrm{G}, 5 \mathrm{G}, 3 \mathrm{G}$, is in a rapid pace of development. In the second generation mobile communication technology, GSM is the most widely used. But GSM system can only carry on the circuit domain data exchange, and the highest transmission rate is $9.6 \mathrm{kbit} / \mathrm{s}$, it is difficult to meet the demand of data service [3].

As a result, the European Telecommunications Standards Board (ETSI) launched the GPRS (Packet Radio Service General, general packet radio service). Packet switching is one of the important data transmission techniques in computer network. In order to achieve from the traditional voice business to support emerging data service, GPRS in the original GSM network based on the superposition of the support of high speed packet data network, to the user provide WAP browser (browse on the Internet page), e-mail and other functions, to promote the mobile data services first flying leap development, realizes the data communication technology and mobile communication technology, especially Internet technology the perfect combination of. GPRS is a technology between $2 \mathrm{G}$ and $3 \mathrm{G}$, also known as $2.5 \mathrm{G}$. It's followed by a younger brother, EDGE, known as $2.75 \mathrm{G}$. They lay the foundation for the smooth transition from GSM to $3 \mathrm{G}$. 


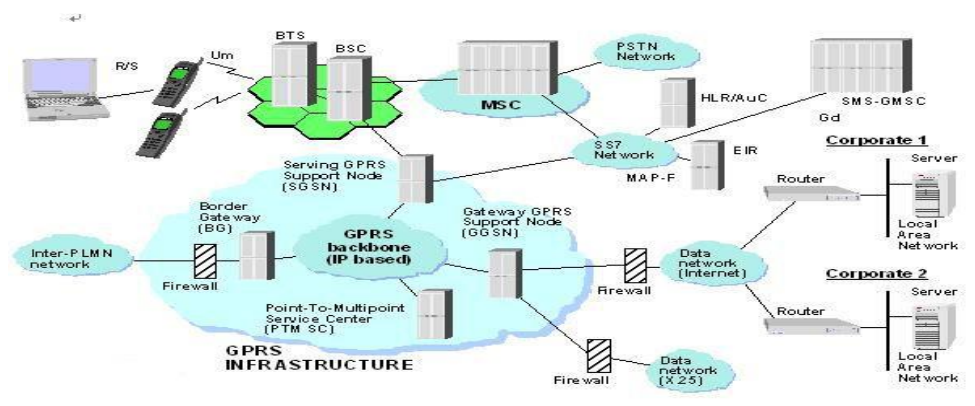

Fig. 2. Schematic diagram of GPRS system

\subsection{Dangerous Goods Logistics Business Process}

Dangerous goods production, were granted the sole product identity information, become a permanent label of the dangerous goods and the dangerous goods production date, period of validity, types, characteristics, storage conditions, transportation conditions, use and destruction condition information stored in the RFID tag card. When the dangerous goods need to be stored in the warehouse, through the RFID card reader, quick access to dangerous goods information, partition storage, and adjust the warehouse environment, so that it can adapt to the storage conditions of the goods. Dangerous goods storage, a library needs to be registered, and the identity of the person in and out of the warehouse identification, authorization decision, behavior records, and the flow of dangerous goods to register, to prevent the loss of dangerous goods. Real time monitoring of the transportation of dangerous goods to ensure the safety of dangerous goods in the transport of dangerous goods transport accidents [4].

Combined with the characteristics of the logistics of dangerous goods and the general principles of the operation of the logistics industry, the logistics of dangerous goods should have the characteristics of safety, information, intelligence, and strict scientific management. Unlike the general logistics focus on efficiency and effectiveness, the first consideration is the safety of dangerous goods logistics. Information and intelligence has gradually become the focus of logistics management, network technology to build information platform allows managers supervise the whole process of the whole supply chain and in real-time to ensure supply chain smoothly and goods safety. Logistics operation of the various departments need better coordination and cooperation, supply chain need to be in strict scientific management, to ensure the process of dangerous goods logistics under the premise of ensuring the safety of the orderly.

3 System Scheme Design

Design mainly to the case of M company as the background, the company's main business is civilian blasting equipment products, including explosives, detonators and industrial cable. In the classification of dangerous goods belong to the first class of explosives. Some industrial explosives in the airtight, high temperature and other environments, very easy to break down, if the ventilation conditions are not HERSHEY'S, there may be natural or explosive. Some in the closed state, encountered strong heat high temperature is very easy to cause explosion. And cause the accident of the accident, the main source of the accident can be: friction, impact, lightning, static, stray current. Industrial explosive cable is mainly to avoid the heat in high temperature environment, keep dry and ventilated storage. Therefore, the company's dangerous goods accident occurred in the general transport, storage, loading and unloading, 
handling, etc.. According to the company's dangerous goods storage and transportation conditions, in the design should be combined with the characteristics of the civilian blasting equipment, design a more perfect risk goods logistics full real-time monitoring and management system is, to improve the security and stability of the transport of dangerous goods storage, protect people's property safety, avoid waste of resources. At the same time, improve the efficiency of the company's dangerous goods logistics monitoring system, to ensure the stability and accuracy of the system, reduce the cost of enterprise management. RFID, GPS, GPRS, GIS technology is used to establish the risk goods logistics full real-time monitoring and management system, it using RFID technology to achieve the identification of dangerous goods, contact personnel for identity and access discrimination etc.; GPS, GPRS network technology platform, the realization of dangerous goods transport and storage information real-time sending and receiving, dangerous goods transport vehicles process realtime monitoring and management functions; the use of GIS visualization monitoring and management capabilities. The system consists of three subsystems, which are dangerous goods monitoring center system, dangerous goods storage monitoring system and transportation monitoring system [5].

\section{Conclusion}

The design scheme of real-time monitoring and management of dangerous goods logistics is a comprehensive design scheme of satellite positioning technology, GIS geographic information technology, sensing technology, computer network technology and wireless communication technology. The scheme is composed of dangerous goods storage monitoring system, dangerous goods transportation monitoring system and dangerous goods monitoring center. Dangerous goods storage monitoring system complete dangerous goods information storage and preservation, dangerous goods transport monitoring system mainly use the vehicle terminal to complete the vehicle positioning and trajectory storage and information transmission, monitoring center complete with two other monitoring system of information exchange and data storage.

\section{References}

[1] Sun Tong. The status quo and Countermeasures of the logistics of dangerous goods. trade union Expo, No. 26, pp. 299-299. (2011)

[2] Ren Zheming, Wang Hongshuang. Analysis and Research on the logistics management of dangerous goods. logistics business theory, No. 4, pp. 182-183. (2012)

[3] Yin Hongyan. Dangerous goods logistics mode of. enterprise Herald, No. 9, pp. 133-133. (2010)

[4] Yu Yang, Liang Zhi, Ma Jie, Liang Xiao, Xi Kun Liu and Hai Ming Zhao, Wei Tongjie and Peng Huan. RFID technology in logistics management of hazardous chemical technology demonstration and application. Grain circulation technology, No. 6, pp. 17-22. (2013)

[5] Wang Yadong. Logistics safety monitoring system based on. Technology RFID science and technology information, No. 11, pp. 38-59. (2014) 